\title{
Exploring Selected Factors that Determine Graduation Times in an Undergraduate Programme
}

\author{
Rohini Khareedi, P Manorika Ratnaweera* \\ Discipline of Oral Health, School of Clinical Sciences, Faculty of Health and Environmental Sciences \\ Auckland University of Technology \\ Auckland, New Zealand \\ ${ }^{*}$ Corresponding author's email: manorika.ratnaweera [AT] aut.ac.nz
}

\begin{abstract}
----
Introduction: Timely graduation is of colossal importance to students, universities, and other stakeholders. The purpose of this retrospective study was to examine the time taken to graduate and to determine if pre-enrolment demographic and experiential characteristics of students are predictive of the aggregate grade point average. The secondary purpose of the study was to identify individual aspects between cohorts based on the time taken to complete the course.

Method: The sample for this study included all students enrolled in the Bachelor of Health Science (Oral Health) program at the Auckland University of Technology from 2008 to 2016. The desensitized data was subjected to descriptive and inferential statistical analysis.
\end{abstract}

Results: The mean grade point average in the first year was lowest in the cohort that took five years to complete and highest in the cohort that took three years to complete. Each year's grade point average was positively correlated to the next year's grade point average. The level of prior education and work experience were predictive of the aggregate grade point average in those completing in three years $(P<0.05)$ but not in those completing in four years $(P>0.05)$.

Conclusion: Pre enrollment factors, level of prior education and work experience were predictive of aggregate grade point average in the cohort completing in three years but not in the cohort completing in four years.

Keywords---- predictors, graduation, grade point average

\section{INTRODUCTION}

The benefits of university education extend beyond providing a social and economic advantage to the individual. It has the potential of being transformational for society. University education through its recipients can increase the well-being of the society (1) and hence graduation times at university are of interest to multiple stakeholders, students, parents, patrons, government agencies, academic faculty, community groups, professional bodies, other institutions, and potential employers. In addition to the quality of education and the quality of graduates, timely graduation is of importance to all stake holders and is a measure of a successful university (2). The graduation times could potentially affect funding from stake holders. Furthermore, graduation rates directly impact university rankings and represent a measurement of institutional performance and student success. (3)

Academic progress and time elapsed between enrollment and graduation is influenced by several institutional and individual factors (4). An understanding of these factors could shed light on interventions that can address short comings and facilitate student retention and timely graduation. Some of the factors include demographic and experiential characteristics like gender, ethnicity, age, level of prior education, work experience and factors directly related to study, like the level of engagement and motivation.

Several studies have attempted to identify indicators to explain the time taken to graduate. Some of the indicators that have been investigated include age, gender ethnicity, high school grade point average, first-generation student, choice of subject, institutional policies and practices, university infrastructure, student experiences at university, academic performance at university, among many others (5).

The purpose of this retrospective study was to examine the time taken to graduate and to determine if the set of preenrolment demographic and experiential characteristics is predictive of the aggregate grade point average. The secondary 
purpose of the study was to identify individual aspects between cohorts based on the time taken to complete the course.

\section{MATERIAL AND METHODS}

This is a retrospective quantitative study using desensitized data. Desensitized data were provided by the data custodian for the purpose of this research. Auckland University of Technology Ethics Committee confirmed no ethics approval was required for this research.

\section{Study variables}

The outcome or dependent variable was the aggregate grade point average of students enrolled in the Bachelor of Health Science (Oral Health) program at the Auckland University of Technology from 2008 to 2016. The predictor or independent variables were as follows: age, sex, ethnicity, level of prior education, the place from where prior education was obtained, work experience and the grade point average of each academic year.

\section{Study sample}

The sample for this study included all students enrolled in the Bachelor of Health Science (Oral Health) program at the Auckland University of Technology from 2008 to 2016. The sample consisted of 277 students.

\section{Statistical analysis}

The raw de-identified data were entered into IBM SPSS (Statistical Package for Social Sciences, IBM Corporation, Endicott, NY, USA) version 26 for Windows. The data were subjected to descriptive and inferential statistical tests. The multivariable regression analysis was applied to the aggregate grade point average and the set of predictor variables to determine the degree to which the predictor variables accounted for the outcome variable. The multiple correlations $(R)$ were calculated to indicate the strength of the relationship between the predictor variables and the outcome variable. The coefficient of multiple determination $\left(R^{2}\right)$ was calculated to determine the amount of variance in the outcome variable that could be accounted for by the predictor variables.

\section{RESULTS}

Table 1: Descriptive statistics of the dependent variables

\begin{tabular}{llll}
\hline & $\begin{array}{l}\text { Three years to } \\
\text { complete }\end{array}$ & Four years to complete & Five years to complete \\
\hline Age & Range- (18-49 years) & Range- (19-44 years) & Range- (20-31 years) \\
& Mean -25.97 years & Mean - 24.90 years & Mean - 23.5 years \\
\hline Ethnicity & Asian (85) & Asian (14) & Asian (2) \\
& European (81) & European (4) & Māori (1) \\
& Māori (33) & Māori (2) & Pacifica (1) \\
& Pacifica (20) & Pacifica (3) & Other (2) \\
& Other (21) & Other (5) & \\
\hline Not Stated (2) & Not Stated (1) & Female -5 \\
& Female - 223 & Female -25 & Male -1 \\
\hline Level of prior & Male - 19 & Male -4 & University Education- 1 \\
education & University Education- & University Education- & Secondary Education - \\
& Secondary Education - & Secondary Education - & 5 \\
\hline Place of prior & New Zealand - 195 & New Zealand - 21 & New Zealand - 5 \\
education & Overseas - 47 & Overseas - 28 & Overseas - 1 \\
\hline Work Experience & No - 92 & No - 15 & No - 5 \\
& Yes - 150 & Yes - 14 & Yes - 1 \\
\hline
\end{tabular}

The sample consisted of 277 students, of which 253 were female and 24 were male. The sample consists of 101 Asian students, 85 European students, 36 Māori students, 24 Pacifica students, 28 students were of 'other' ethnicities, 3 students had not stated their ethnicity. Of the 277 students, 130 students had university qualifications prior to enrollment and 147 had declared their highest qualification as having completed secondary school at the time of enrollment. Nearly $80 \%$ 
(221) of the students had obtained prior education in New Zealand and nearly $60 \%$ (165) had work experience. The statistics of the above demographic and experiential characteristics by the years taken to complete is as shown in Table 1. The key findings are that the average age of students who took five years to complete was lower than those taking three or four years to complete. So also, the cohort taking five years to complete had proportionately lesser number of students with prior university education and work experience.

The outcome variable, that is the aggregate grade point average was obtained by calculating the grade point average obtained in each academic year. The normal distribution curve of the outcome variable is evident in Fig (1) and the probability plot in Fig (2) indicates normal distribution. The standard deviation was 1.342.

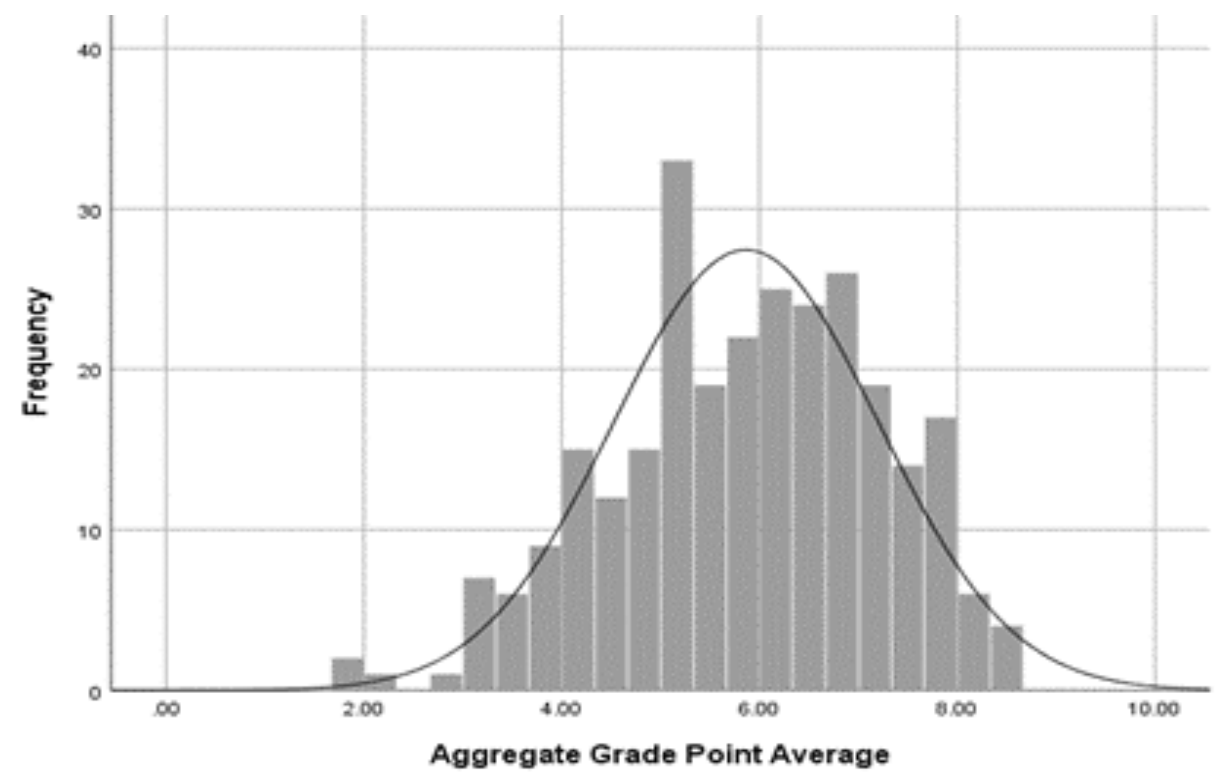

Fig 1: Distribution Curve for the Aggregate Grade Point Average

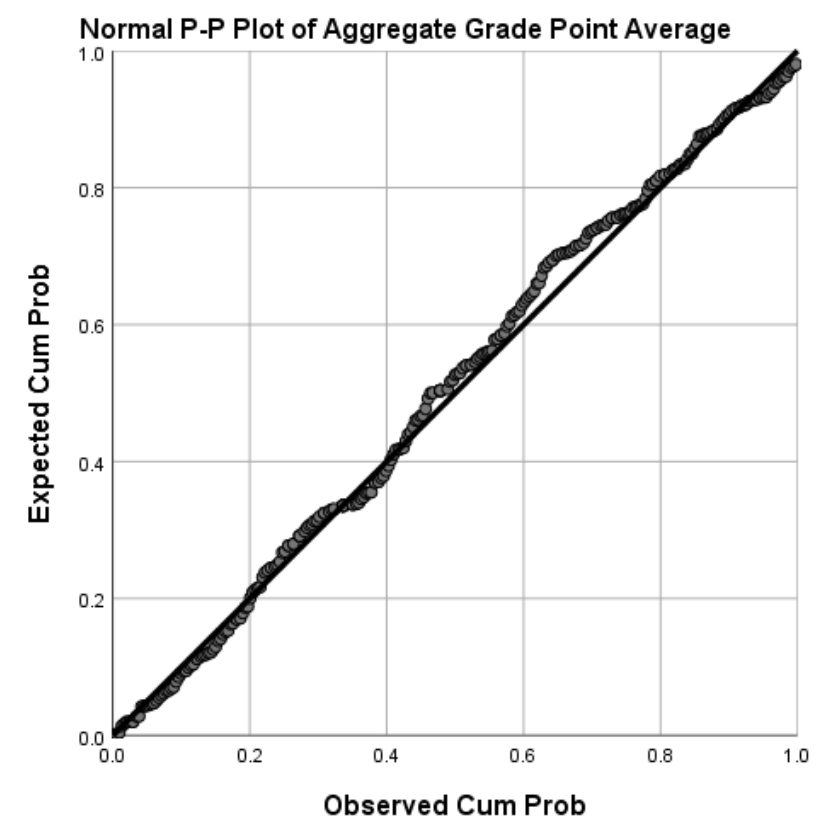

Fig 2: Probability Plot for Aggregate Grade Point Average

The aggregate grade point average was calculated by calculating the average of the grade point average obtained in each year. The positive correlation between each year's grade point average in those taking three years to complete and those taking four years to complete is shown in Fig (3) and in Fig (4). 


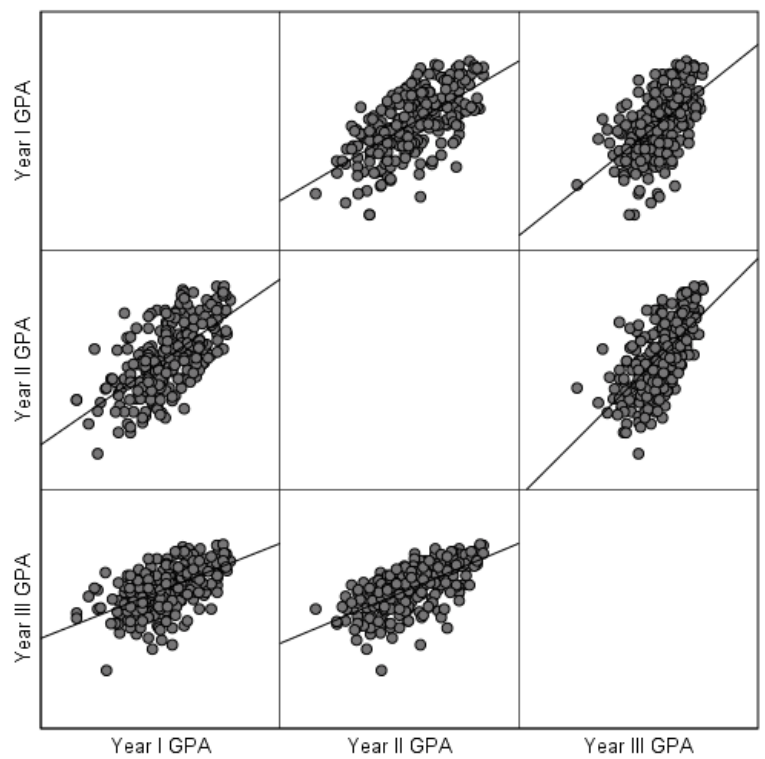

Fig 3: Scatter plot for grade point averages of first, second, and third year (3 years to complete)

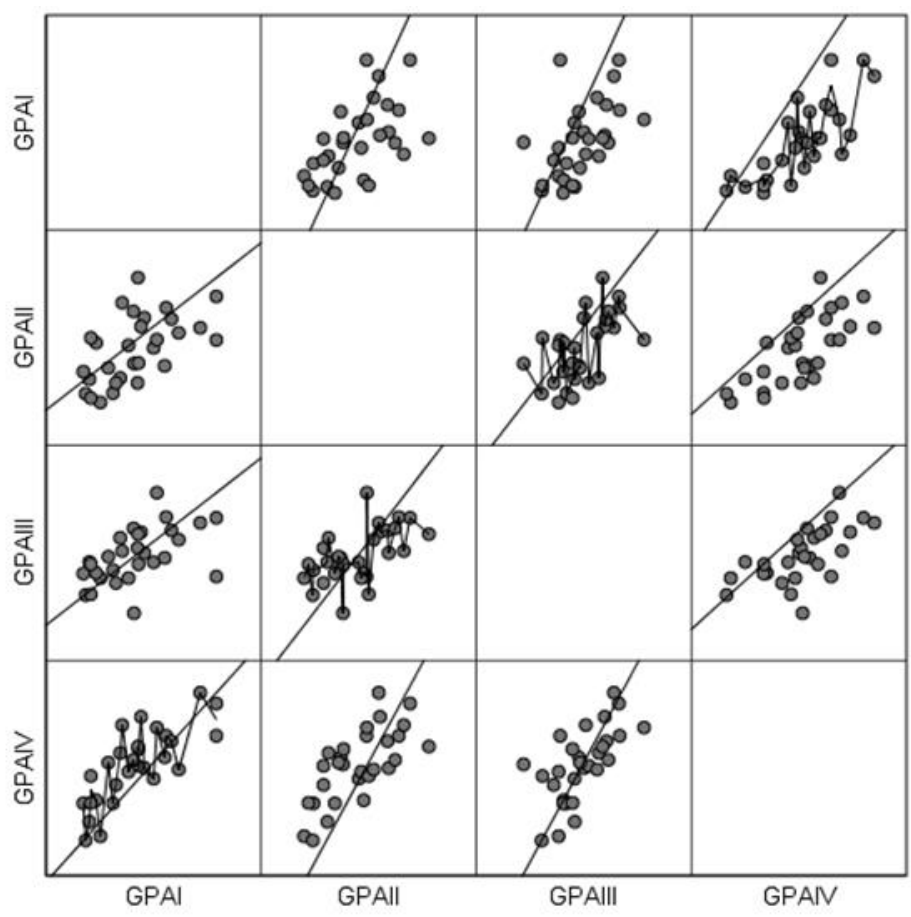

Fig 4: Scatter plot for grade point averages of first, second, third year and fourth year (4 years to complete)

Of the 277 students, 242 students completed the course in three years, 29 students completed the course in four years and six students completed the course in five years. The mean of the aggregate grade point average and mean grade point average in the first year in each of these categories is shown in Table 2. 
Table 2: Time taken to complete course and mean first year grade point average mean aggregate grade point average.

\begin{tabular}{llll}
\hline $\begin{array}{l}\text { Total number of } \\
\text { students }\end{array}$ & $\begin{array}{l}\text { Duration to } \\
\text { complete }\end{array}$ & $\begin{array}{l}\text { Mean GPA of the first } \\
\text { year }\end{array}$ & $\begin{array}{l}\text { Mean of the } \\
\text { Aggregate GPA }\end{array}$ \\
\hline $\mathbf{2 4 2}$ & 3 years & 5.83 & 6.06 \\
\hline $\mathbf{2 9}$ & 4 years & 4.28 & 4.75 \\
\hline $\mathbf{6}$ & 5 years & 3.30 & 3.27 \\
\hline
\end{tabular}

Pearson's correlation coefficient was calculated between age, gender, ethnicity, work experience, level of education, place of prior education and the aggregate grade point average in those completing the course in three years and those completing in four years.

The correlation between the aggregate grade point average and age for those completing the course in 3 years is statistically significant as Sig (two- tailed) at 0.02 is lesser than 0.05 as shown in Table 3. The $\mathrm{r}$ value of 0.194 at $\mathrm{P}<$ 0.001 indicates that change in one variable is positively correlated with changes in the other. However, age is not statistically significantly correlated with aggregate grade point average for those completing in four years.

Table 3: Correlation between age and Aggregate GPA (3 years to complete)

\begin{tabular}{|c|c|c|c|}
\hline & & Age & Aggregate GPA \\
\hline \multirow[t]{3}{*}{$\overline{\text { Age }}$} & Pearson Correlation & 1 & $0.194 * *$ \\
\hline & Sig. (2-tailed) & & 0.002 \\
\hline & $\mathrm{N}$ & 242 & 242 \\
\hline \multirow[t]{3}{*}{ Aggregate GPA } & Pearson Correlation & $0.194 * *$ & 1 \\
\hline & Sig. (2-tailed) & 0.002 & \\
\hline & $\mathrm{N}$ & 242 & 242 \\
\hline
\end{tabular}

The correlation between the aggregate grade point average and the level of prior education in those taking three years to complete is statistically significant as Sig (two- tailed) at 0.000 is lesser than 0.05 as shown in Table 4 . The $r$ value of 0.273 at $P<0.001$ indicates that change in one variable is correlated with changes in the other. The mean of the aggregate grade point average in those with university qualifications was 6.40 while in those with only secondary school qualifications was 5.75. However, in those taking four years to complete there was no statistically significant correlation between the level of prior education and the aggregate grade point average.

Table 4: Correlation between level of prior education and Aggregate GPA (3 years to complete)

\begin{tabular}{l|ccc}
\hline \multirow{2}{*}{ Aggregate GPA } & Aggregate GPA & Prior Education \\
& Pearson Correlation & 1 & $-0.273^{* *}$ \\
\cline { 2 - 4 } & Sig. (2-tailed) & & 0.000 \\
\cline { 2 - 4 } & $\mathrm{N}$ & 242 & 242 \\
\hline \multirow{2}{*}{ Prior Education } & Pearson Correlation & $-0.273^{* *}$ & 1 \\
\cline { 2 - 4 } & Sig. (2-tailed) & 0.000 & 242 \\
\cline { 2 - 4 } & $\mathrm{N}$ & 242 & \\
\hline
\end{tabular}

Aggregate grade point average and work experience is statistically significant as Sig (two- tailed) at 0.000 is lesser than 0.05 as shown in Table 5 for those completing the course in three years and for those completing in four years (Table 6) The negative $r$ value of -0.222 for those completing in three years and the $r$ value of -0.427 for those completing in four years at $P<0.001$ indicates that change in one variable is correlated to changes in the other. The mean aggregate grade point average of those completing in three years with work experience is 6.26 while in those without work experience is 
5.72. Similarly, in those completing in four years, the mean aggregate grade point average in those with work experience was 5.42 and it was 4.13 in those without work experience.

Table 5: Correlation between work experience and Aggregate GPA (3 years to complete)

\begin{tabular}{llrr}
\hline & & Aggregate GPA & Work Experience \\
\hline Aggregate GPA & Pearson Correlation 1 & $-0.222^{* *}$ & \\
\cline { 2 - 4 } & Sig. (2-tailed) & 242 & 0.000 \\
\cline { 2 - 4 } Work Experience & Pearson Correlation & $-0.222^{* *}$ & 242 \\
\cline { 2 - 4 } & Sig. (2-tailed) & 0.000 & 242 \\
\cline { 2 - 4 } & $\mathrm{N}$ & 242 & 242 \\
\hline
\end{tabular}

Table 6: Correlation between work experience and Aggregate GPA (4 years to complete)

\begin{tabular}{llrr}
\hline & & Aggregate GPA & Work Experience \\
\hline Aggregate GPA & Pearson Correlation & 1 & $-0.427^{*}$ \\
\cline { 2 - 4 } & Sig. (2-tailed) & 29 & 0.021 \\
\cline { 2 - 4 } Work Experience & Pearson Correlation & $0-0.427^{*}$ & 29 \\
\cline { 2 - 4 } & Sig. (2-tailed) & 0.021 & 1 \\
\cline { 2 - 3 } & $\mathrm{N}$ & 29 & 29 \\
\hline
\end{tabular}

*. Correlation is significant at the 0.05 level (2-tailed).

The regression analysis was carried out using the aggregate grade point average as the outcome variable and age, gender, ethnicity, level of prior education, place of prior education, work experience as dependent variables with two models, one for those completing the course in three years and one for those completing the course in four years.

As shown in Table 8, though $15.4 \%$ of variation in the outcome variable in students completing in three years could be due to the dependent variables, only work experience, gender and level of prior education were statistically significant $(\mathrm{P}<0.05)$ as shown in Table 7.

Table 7: Regression analysis with age, gender, ethnicity, place and level of prior education and work experience as independent variables and aggregate GPA as dependent variable (3-year completion)

\begin{tabular}{|c|c|c|c|c|c|}
\hline \multirow[b]{2}{*}{ Model } & \multicolumn{2}{|c|}{ Unstandardized Coefficients } & \multirow{2}{*}{$\begin{array}{c}\begin{array}{c}\text { Standardized } \\
\text { Coefficients }\end{array} \\
\text { Beta }\end{array}$} & \multirow[b]{2}{*}{$\mathbf{T}$} & \multirow[b]{2}{*}{ Sig. } \\
\hline & $\mathbf{B}$ & Std. Error & & & \\
\hline (Constant) & 7.979 & 0.583 & & 13.692 & 0.000 \\
\hline Age & 0.022 & 0.011 & 0.131 & 1.897 & 0.059 \\
\hline Ethnicity & -0.051 & 0.058 & -0.055 & -0.888 & 0.375 \\
\hline Gender & -0.752 & 0.274 & -0.170 & -2.746 & 0.006 \\
\hline Prior Education & -0.545 & 0.165 & -0.228 & -3.292 & 0.001 \\
\hline Place of Prior Education & -0.077 & 0.208 & -.025 & -0.368 & 0.713 \\
\hline Work Experience & -0.442 & 0.156 & -0.180 & -2.828 & 0.005 \\
\hline
\end{tabular}

a. Dependent Variable: Aggregate GPA 
Table 8: Regression Model Summary (3-year completion)

\begin{tabular}{|c|c|c|c|c|}
\hline Model & $\mathbf{R}$ & R Square & $\begin{array}{l}\text { Adjusted R } \\
\text { Square }\end{array}$ & Std. Error of the Estimate \\
\hline & $0.393 a$ & 0.154 & 0.132 & 1.11132 \\
\hline
\end{tabular}

a. Predictors: (Constant), Work Experience, Age, Ethnicity, Gender, Place of Prior Education, Prior Education

As shown in Tables 9 and 10, though $24.4 \%$ of variation in the outcome variable in students completing in four years could be due to the dependent variables, none of the variables were statistically significantly predictive $(\mathrm{P}>0.05)$.

Table 9: Regression analysis with age, gender, ethnicity, place and level of prior education and work experience as independent variables and aggregate GPA as dependent variable (4-year completion)

\begin{tabular}{|c|c|c|c|c|c|}
\hline \multirow[b]{2}{*}{ Model } & \multirow{2}{*}{\multicolumn{3}{|c|}{$\begin{array}{c}\begin{array}{c}\text { Standardized } \\
\text { Coefficients }\end{array} \\
\text { Beta } \\
\end{array}$}} & \multirow[b]{2}{*}{$\mathbf{t}$} & \multirow[b]{2}{*}{ Sig. } \\
\hline & & & & & \\
\hline (Constant) & 6.868 & 2.534 & & 2.710 & 0.013 \\
\hline Age & 0.053 & 0.057 & 0.227 & 0.928 & 0.363 \\
\hline Ethnicity & 0.063 & 0.120 & 0.098 & 0.526 & 0.604 \\
\hline Gender & -0.504 & 0.894 & -0.115 & -0.564 & 0.579 \\
\hline Prior Education & -0.484 & 0.763 & -0.159 & -0.634 & 0.532 \\
\hline $\begin{array}{l}\text { Place of prior } \\
\text { Education }\end{array}$ & -0.912 & 0.864 & -0.270 & -1.055 & 0.303 \\
\hline $\begin{array}{l}\text { Work } \\
\text { Experience }\end{array}$ & -0.829 & 0.716 & -0.274 & -1.157 & 0.260 \\
\hline
\end{tabular}

a. Dependent Variable: Aggregate GPA

Table 10: Regression Model Summary (4-year completion)

\begin{tabular}{rr|rrr}
\hline Model & R & R Square & $\begin{array}{c}\text { Adjusted R } \\
\text { Square }\end{array}$ & \multicolumn{2}{c}{$\begin{array}{c}\text { Std. Error of the } \\
\text { Estimate }\end{array}$} \\
\hline & $0.494 \mathrm{a}$ & 0.244 & 0.038 & 1.50661 \\
\hline
\end{tabular}

a. Predictors: (Constant), Work Experience, Place of prior Education, Ethnicity,

Gender, Age, Prior Education

\section{DISCUSSION}

The results of this study comparing the demographic and experiential characteristics of students at enrolment and the academic performance at university with the time taken to complete has shown that the grade point average of each year is positively correlated to the grade point average of the following year in those completing the course in three years and in those completing the course in four years. The first-year grade point average between the three cohorts; those completing in three, four and five years shows a clear variation with the lowest being in those taking five years to complete. The two models of the regression analysis with all variables revealed that work experience and level of prior education were statistically significant predictor variables for those completing the course in three years.

The results of both the univariate and multi variate regression models on those completing the course in three years have revealed that the level of prior education and work experience are predictive of the aggregate grade point average. This finding of prior university education being predictive is similar to a study in 2003 with one hundred and ninety-two chiropractic students, students already possessing university qualifications had higher grades point averages (6). A 2010 study on medical students found that a greater number of graduate entry students successfully completed the final examination (7). However, a study of medical students in a Queensland university did not find prior university qualifications particularly advantageous (8). Our finding of work experience being a predictor of aggregate grade point 
average is similar to the results obtained in a study on the academic performance of accounting students, which concluded that exposure to work environments may potentially sharpen analytical skills (9).

Our findings of background characteristics in those completing in four years not being predictive of aggregate grade point average is comparable to the findings of Bartlett, Peel and Pendlebury (10). This implies a potential conclusion that attributes developed at university may have had a role in the academic performance rather than the background characteristics that has been taken into consideration for students taking four years to complete. Yue and Fu in their study also found that the pre-enrolment factors did not influence student performance at university (4).

Our findings of each year's grade point average being positively correlated to the grade point average in the following year is akin to the findings by Bartlett et al in their study. Their conclusion was that the best predictor of academic performance in the final year is academic achievement in earlier university examinations (10) and these conclusions are also comparable to the conclusions drawn from a longitudinal study of university students in New Zealand (11). In addition, Tickell and Smyrnios in their 2005 study found that the previous year's academic performance is the most significant positive predictor for the grade point average of the current year (12). So also, Ye and Fu in their study on time taken to obtain a degree have found that academic performance is the most important factor in determining graduation times (4). Similarly, a study of undergraduate dental students in Western Australia found that the previous year's academic performance had a strong relationship with yearly weighted average marks (13).

The comparison of the first-year grade point average has revealed that the cohort taking five years to graduate had the lowest average compared to the other two cohorts. The cohort that graduated in three years has higher first year grade point average than the cohort that took four years to graduate. This finding is in line with the findings of Tentsho et al's study in 2018 (1), who have concluded that early academic performance is significant in predicting timely graduation and interventions to encourage better performance in the first year are expected to help with timely graduation. This finding of first year GPA being inversely associated with the duration taken for the course is similar to Yue and Fu's finding of lowgrade point average being associated with fewer credits each term and longer overall course time (4).

The limitations of this study are the small sample size and the limited number of predictor variables used and hence though the conclusions cannot be generalised, though it has implications for education practice and future research. Inferential statistical analysis could not be applied to the sample taking five years to complete due to the small sample size. A replication of the same study in other universities offering the same course and in other courses may help to ascertain the findings.

The conclusion from the results obtained in our study is that previous year's grade point average is positively correlated to the next year's grade point average. The first-year grade point average was the highest in the cohort taking three years to complete and lowest in the cohort taking five years to complete. The level of prior education and work experience was predictive of aggregate grade point average in those completing the course in three years but not in those taking four years.

\section{REFERENCES}

1. Tentsho, K., McNeil, N., \& Tongkumchum, P. (2019). Examining timely graduation rates of undergraduate students. Journal of Applied Research in Higher Education, 11(2), 199-209. doi: 10.1108/JARHE-10-2017-0124

2. Crisp, G., Doran, E., \& Salis Reyes, N. A. (2018). Predicting Graduation Rates at 4-Year Broad Access Institutions Using a Bayesian Modeling Approach. Research in Higher Education, 59(2), 133-155.

3. Oztekin, A. (2016). A hybrid data analytic approach to predict college graduation status and its determinative factors. Industrial Management \& Data Systems, 116(8), 1678.

4. Yue, H., \& Fu, X. (2017). Rethinking Graduation and Time to Degree: A Fresh Perspective. Research in Higher Education, 58(2), 184-213.

5. Su, X., Chen, M., Yur-Austin, J., \& Liu, Y. (2020). Restructuring degree roadmaps to improve timely graduation in higher education. International Journal of Educational Management, 34(2), 432.

6. Green, B. N., Johnson, C. D., \& McCarthy, K. (2003). Predicting academic success in the first year of chiropractic college. Journal of Manipulative and Physiological Therapeutics, 26(1), 40-46. doi: 10.1067/mmt.2003.9

7. Shehmar, M., Haldane, T., Price-Forbes, A., Macdougall, C., Fraser, I., Peterson, S., \& Peile, E. (2010). Comparing the performance of graduate-entry and school-leaver medical students: Comparison of graduate-entry and school-leaver students. Medical Education, 44(7), 699-705. doi: 10.1111/j.1365-2923.2010.03685.x

8. Harth, S. C., Biggs, J. S., \& Thong, Y. H. (1990). Mature-age entrants to medical school: a controlled study of sociodemographic characteristics, career choice and job satisfaction. Medical Education, 24(6), 488-498.

9. Koh, M. Y., \& Koh, H. C. (1999). The determinants of performance in an accountancy degree programme. Accounting Education, 8(1), 13-29. doi: 10.1080/096392899331017

10. Bartlett, S., Peel, M. J., \& Pendlebury, M. (1993). From fresher to finalist1. Accounting Education, 2(2), $111-122$. doi: 10.1080/09639289300000013 
11. Tumen, S., Shulruf, B., \& Hattie, J. (2008). Student Pathways at the University: Patterns and Predictors of Completion. Studies in Higher Education, 33(3), 233-252.

12. Tickell, G., \& Smyrnios, K. X. (2005). Predictors of Tertiary Accounting Students' Academic Performance: A comparison of Year 12-to-university students with TAFE-to-university students. Journal of Higher Education Policy \& Management, 27(2), 239-259. https://doi.org/10.1080/13600800500120142

13. Mercer, A., Abbott, P. V., \& Puddey, I. B. (2013). Relationship of selection criteria to subsequent academic performance in an Australian undergraduate dental school. European Journal of Dental Education, 17(1), 39-45. doi: 10.1111/eje.12005 